УДК 342.92

DOI https://doi.org/10.17308/vsu.proc.law.2020.3/2980

\title{
ВЫЯВЛЕНИЕ СИСТЕМНЫХ ПРАВОВЫХ ОГРАНИЧЕНИЙ ЦИФРОВИЗАЦИИ ГОСУДАРСТВЕННОГО УПРАВЛЕНИЯ: ТЕКУЩЕЕ СОСТОЯНИЕ И ПЕРСПЕКТИВЫ
}

\author{
В. Н. Южаков, А. А. Ефремов
}

Российская акаделия народного хозяйства и государственной службы при Президенте РФ

Поступила в редакцию 29 июня 2020 г.

\begin{abstract}
Аннотация: в статье, подготовленной на основе научно-исследовательской работы, выполняелой в ралках государственного задания РАНХиГС, рассмотрены существующие норлотворческие и управленческие подходы $\kappa$ выявлению и устранению правовых ограничений иибровизаиии государственного управления. Предложены оценка совреленного состояния ее решения и реколендации по коррекиии реализуелых в настоящее вреля подходов к решению этой задачи.

Ключевые слова: государственное управление, мониторинг правоприленения, правовые ограничения, правовые экспериленты, "регуляторная гильотина», стратегическое планирование, иифровизация, иифровая трансбормаиия.
\end{abstract}

\begin{abstract}
: the article discusses the existing normative and managerial approaches to identifying and eliminating legal restrictions for digitalization of public administration. An assessment of the current state of its solution and recommendations on the correction of approaches currently being implemented to solve this problem are proposed. legal experiments; "Regulatory guillotine"; strategic planning; digitalization digital transformation.
\end{abstract}

Исследование проблем выявления и устранения правовых ограничений для осуществления цифровизации и цифровой трансформации в последние годы актуализировалось в связи как с развитием самих цифровых технологий, так и задачами по их внедрению, определенными в документах стратегического планирования РФ в 2017-2020 гг. В частности, Стратегия развития информационного общества в Российской Федерации на 2017-2030 гг. определяет необходимость соответствия нормативно-правового регулирования темпам развития цифровой экономики и устранения административных барьеров. Указ Президента Российской Федерации от 7 мая 2018 г. № 204 «О национальных целях и стратегических задачах развития Российской Федерации на период до 2024 года» (п. 11) определяет необходимость создания системы правового регулирования цифровой экономики, основанного на гибком подходе в каждой

(C) Южаков В. Н., Ефремов А. А., 2020 
сфере, а также внедрение цифровых технологий и платформенных решений в сферах государственного управления и оказания государственных услуг. Основные направления деятельности Правительства РФ на период до 2024 г. также содержат указанные задачи.

Реализация задач по внедрению цифровых технологий в государственное управление требует снятия существующих и возникающих новых правовых ограничений для цифровой трансформации фрункций и полномочий органов государственной власти, при этом ключевой целью указанных задач является повышение результативности и эффрективности государственного управления в России.

Несмотря на значительное развитие научных исследований в сфере правового регулирования цифровых технологий ${ }^{1}$ до настоящего времени в российском нормотворческом процессе и правоприменительной практике отсутствует механизм выявления и устранения системных правовых ограничений для внедрения цифровых технологий (цифровизации) в государственном управлении и отдельных отраслях экономики.

В российской юридической науке не сложилось единого понимания правовых ограничений. Под ними понимается, в том числе, правовое сдерживание противозаконного деяния²; юридические инструменты, обеспечивающие достижение целей правового регулирования ${ }^{3}$ установление государством законодательных пределов осуществления прав и свобод ; пределы разрешенного нормами права вариантов поведения фризических и юридических лиц, которые носят исключительно временный, пространственный и субъективный характер ${ }^{5}$. При этом целевым ориентиром для ограничения субъективных прав рассматривается, как правило, необходимость защиты основ конституционного строя, нрав-

${ }^{1}$ Правовое регулирование цифровых технологий в России и за рубежом. Роль и место правового регулирования и саморегулирования в развитии цифровых технологий / под общ. ред. А. В. Минбалеева. Саратов, 2019 ; Наулов В. Б. Общие вызовы права и государственного управления в цифровую эпоху // Ленингр. юрид. журнал. 2019. № 1 (55). С. 43-57 ; Его же. Право в эпоху правовой трансформации : в поисках решений // Рос. право : образование, практика, наука. 2018. № 6. С. 4-11; Полякова Т. А., Минбалеев А. В. Цифровые инновации и проблемы развития механизма правового регулирования в России // Информационное право. 2019. № 4. С. 12-15.

${ }^{2}$ См.: Малько А. В. Стимулы и ограничения в праве. 2-е изд., перераб. и доп. M., 2003. C. 142.

${ }^{3}$ См.: Шемаров В. А. Сущность, понятие, признаки и виды правовых ограничений // Вестник общественной науч.-исслед. лаборатории «Взаимодействие уголовно-исполнительной системы с институтами гражданского общества : историко-правовые и теоретико-методологические аспекты». 2017. № 9. С. 181-190.

${ }^{4}$ См.: Маковеикая М. Г. Понятие правовых ограничений прав и свобод человека // Вестник Нижегородского ун-та имени Н. И. Лобачевского. 2012. № 6 (1). C. 236 .

${ }^{5}$ См.: Басова Ю. Ю. Теоретико-правовые подходы к определению понятия «ограничение» // Успехи современной науки. 2017. Т. 6, № 2. С. 12-15. 


\section{Вестник ВГУ. Серия: Право}

ственности, здоровья, прав и законных интересов других лиц, обеспечения обороны страны и безопасности государства ${ }^{6}$.

Рассмотрение содержания конкретных правовых ограничений для деятельности отдельных субъектов социально-экономических отношений, в том числе в сфере государственного управления, в современной юридической науке носит преимущественно отраслевой характер. Единичные исследования, посвященные системности правовых ограничений, связаны с системностью не самих ограничений, а их места в системе правового регулирования отдельных субъектов или объектов общественных отношений ${ }^{7}$.

Классификация правовых ограничений в юридической науке осуществляется по различным основаниям, в том числе по отраслевой принадлежности, субъектам права, времени действия, степени обоснованности ${ }^{8}$.

B сфбере инфборлационных отношений классификация ограничений осуществляется через ограничения прав субъектов на доступ к информации ${ }^{9} ;$ распространение информации ${ }^{10} ;$ тайну ${ }^{11}$.

А. В. Минбалеев, характеризуя ограничения в процесс регулирования цифровых технологий ${ }^{12}$, выделяет ограничения, связанные с отсут-

${ }^{6}$ См.: Травников Н. О. «Предел» и «ограничение» в праве : теоретико-правовой анализ понятий // Государство и право. 2017. № 7. С. 104-109.

${ }^{7}$ См.: Макогон Б. В. Системное единство правовых ограничений в процессе фонкционирования органов внутренних дел России как публичных властных субъектов // Наука и образование : хозяйство и экономика; предпринимательство; право и управление. 2016. № 3 (70). С. 16-20.

${ }^{8}$ См.: Осипов М. Ю., Оськина С. В. Ограничения в праве как элемент управления : понятие и правовая природа // Современные проблемы права, экономики ๓ и управления. 2018. № 1 (6). С. 101-111.

${ }^{9}$ См.: Махотина Н. В. Нормативно-правовое обеспечение в области ограничения доступа к информации в РФ // Символ науки. 2015. № 10-1. С. 133-135 ; Бабашкина В. С. Метод и методология при проведении исследования конституционно-правового регулирования ограничения права на информацию в РФ и Германии // Устойчивое развитие науки и образования. 2017. № 3. С. 20-25.

10 См.: Паламарчук C. A. Вопросы нормативно-правового регулирования

158 цензуры как одного из видов ограничения права на информацию // Северо-Кавказский юридический вестник. 2017. № 1. С. 141-147 ; Гонежук 3. Н. Основные правовые подходы к регулированию ограничений распространения информации в сети «Интернет» // Политематический сетевой электронный научный журнал Кубанского гос. аграрного ун-та. 2015. № 114. С. 717-726 ; Бутин А. А. Правовые основы ограничения распространения информации в сети «Интернет» // NovaUm. Ru. 2018. № 16. C. 359-362.

${ }^{11}$ См.: Терехов М. Ю., Григорьев И. Б. Ограничения права каждого на тайну сообщений : к вопросу о реализации конституционно-правовых норм в уголовно-процессуальном законодательстве // Алтайский юрид. вестник. 2015. № 2 (10). C. 93-97.

${ }^{12}$ См.: Правовое регулирование цифровых технологий в России и за рубежом. Роль и место правового регулирования и саморегулирования в развитии цифровых технологий / под общ. ред. А. В. Минбалеева. Саратов, 2019. 
ствием понятийного аппарата в сфере регулирования цифровых технологий; неопределенность моделей регулирования цифровых технологий; технические ограничения.

Характеризуя содержание правовых ограничений, в том числе в сфрере государственного управления, необходимо выделить три их уровня:

- ограничение инфборлатизаиии государственного управления (в том числе требования о «бумажных носителях» документов, «письменной фороме»);

- ограничение иифровизаиии (т. е. применения в государственном управлении прорывных цифровых технологий - обработки больших объемов данных, искусственного интеллекта, распределенного реестра);

- ограничение иифровой трансфборлаиии государственного управления (изменение задач, функций, организации государственного управления $)^{13}$.

Ранее проведенный анализ правовых ограничений цифровизации государственного управления в отношении отдельных сфер деятельности ${ }^{14}$ показал, что наряду с правовыми нормами, создающими затруднения или прямые препятствия для цифрровизации именно в этих сферах деятельности (которые можно было бы назвать частными ограничениями), существуют и правовые ограничения для цифровизации, которые действуют в нескольких или предположительно всех сырерах деятельности и которые можно назвать системными правовыми ограничениями цифровизации. Одним из наиболее ярких примеров системного правового ограничения цифровой трансформации является ориентация практически всех сфер деятельности и управления, в том числе государственного управления, на применение документов, а не оборот данных, в связи с чем большая часть задач по цифровизации сводится к внедрению электронного документооборота и оцифровке существующих бизнес-процессов и административных процедур на основе электронных документов.

С учетом этого в настоящей статье под системными правовыми ограничениями цифровизации государственного управления понимаются положения нормативных правовых актов, препятствующие применению цифровых технологий субъектами государственного управления в рамках осуществления ими полномочий по государственному управлению в отношении ряда или всех сфер деятельности в отношении которых осуществляется государственное управление.

${ }^{13}$ См.: Южаков В. Н., Талапина Э. В., Ебрелов А. А. Правовые ограничения для использования прорывных цифровых технологий в государственном управлении // Вестник Рос. ун-та дружбы народов. Серия: Государственное и муниципальное управление. 2018. Т. 5, № 3. С. 235-247 ; Цифровое будущее государственного управления по результатам / Е. И. Добролюбова [и др.]. М., 2019.

${ }^{14}$ См.: Южаков B. Н., Ефрелов А. А. Правовые и организационные барьеры для цифровизации образования в Российской Федерации // Рос. право : образование, практика, наука. 2018. № 6 (108). С. 18-24; Ефрелов А. А. Правовые ограничения цифровизации научной деятельности // Юрид. мир. 2019. № 2. С. 49-53. 


\section{Вестник ВГУ. Серия: Право}

Предположительно, системные правовые ограничения государственного управления могут возникать в отношении любых параметров организации государственного управления, в том числе в отношении:

- отдельных административных процедур (например, издания административных актов), «сквозных» для всех видов государственных функций или некоторых из них, или какого-либо из них;

- отдельных стадий управленческого цикла государственного управления, также «сквозных» для всех видов государственных фуннций или некоторых из них, или какого-либо из них;

- отдельных видов государственных функций в целом;

- организации государственного управления в целом.

Соответственно, отслеживание, поиск и при необходимости устранение системных правовых ограничений цифровизации государственного управления должны проводиться в отношении всех этих параметров организации государственного управления.

При этом установленные отдельными нормативными правовыми актами ограничения применения цифровых технологий в рамках отдельных административных процедур, не являющихся «сквозными» для всех видов государственных функций или этапов управленческого цикла государственного управления, не могут рассматриваться как системные.

На предмет возможных системных правовых ограничений освоения в государственном управлении должны рассматриваться все направления развития прорывных цифровых технологий и их актуальные приложения, в которых формируются практически применимые возможности цифровизации, в том числе цифровой трансформации государственного управления.

В настоящее время развитие правового регулирования цифровых технологий, в том числе выявление правовых ограничений для их применения, осуществляется в рамках реализации документов стратегического планирования (главным образом, национальной программы «Цифровая экономика Российской Федерации»), проведения оценки регулирующего и фактического воздействия, мониторинга правоприменения, реализации механизма "регуляторной гильотины», проведения экспериментов в

160 сфере применения цифровых технологий.

160 В рамках национальной программы «Цифровая экономика Российской Федерации» паспорт федерального проекта «Цифровое государственное управление», утв. президиумом Правительственной комиссии по цифровому развитию, использованию информационных технологий для улучшения качества жизни и условий ведения предпринимательской деятельности, от 28 мая 2019 г. протокол № 9, предусматривает только устранение ограничения «для вынесения нескольких исполнительных докулентов в фборле әлектронного докулента».

Президиум правительственной комиссии по цифровому развитию 12 марта 2020 г. утвердил план-график, который предусматривает внесение изменений в 42 нормативно-правовых актах, регламентирующих оказание отдельных государственных услуг, при этом такие изменения 
связаны, как правило, только с предоставлением возможности направления электронных документов вместо бумажных, а не с цифровой трансформацией соответствующих государственных услуг.

Еще одним направлением выявления правовых ограничений цифровизации государственного управления в рамках разработки и реализации документов стратегического планирования является разработка ведолственных програлмл иифбровой трансфборлаиии. При этом разработанный в апреле 2020 г. проект постановления Правительства РФ «О мерах по обеспечению эффрективности мероприятий по использованию информационно-коммуникационных технологий в деятельности государственных органов" не содержит определения понятия «иифровая трансфорлация", соотношения упоминаельх "трансфбормируемьхх процессов" с понятияли "государственная фбункиия", "государственная услуга", "административная процедура» ${ }^{15}$.

Вместе с тем механизм формирования и реализации ведомственных программ цифрровой трансформации, предусматривающий разработку нормативных правовых актов, необходимьх для реализации соответствующих мероприятий иифровой трансфбормации, может являться основой для создания механизла выявления систелных правовых ограничений иифровизации и иифровой трансфбормации государственного управления.

В рамках механизма оценки регулирующего воздействия (ОРВ) проектов нормативных правовых актов выявление правовых ограничений, системных правовых ограничений циоровизации, в том числе государственного управления, прямо не предусмотрено и возможно только в тех случаях, когда указанные ограничения создают обязанности, запреты $u$ ограничения для фризических и юридических лиц в сфере предпринимательской и иной экономической деятельности, а также способствуют возникновению необоснованных расходов физических и юридических лиц. Кроме того, выявление системных правовых ограничений затруднено также тем, что ОРВ проводится в отношении конкретных проектов нормативных правовых актов, а не правовых институтов или, применительно к государственному управлению, отдельных государственных фрункций, не позволяет выявлять системные правовые ограничения цифровизации государственного управления. Вместе с тем в рамках ОРВ предусматри$\infty$ вается выявление рисков решения проблелы предложенным способом регулирования и рисков негативных последствий, что целесообразно учитывать при разработке механизма выявления системных правовых ограничений цифровизации государственного управления.

${ }^{15}$ См.: Eбрелиов A. A. Заключение по результатам независимой антикоррупционной экспертизы проекта постановления Правительства Российской Федерации «О мерах по обеспечению эфрфективности мероприятий по использованию инорормационно-коммуникационных технологий в деятельности государственных органов». URL: https://to36.minjust.ru/sites/default/files/efremov_aa_ake_zakl_ mincifra_proekt_pp_ikt_100840.pdf 


\section{Вестник ВГУ. Серия: Право}

В рамках механизма оценки фрактического воздействия (ОФВ) действующих нормативных правовых актов выявляются положения, необоснованно затрудняющие ведение предпринимательской и иной экономической деятельности или приводящие к возникновению необоснованных расходов бюджетов бюджетной системы Российской Федерации. При этом ни в одном случае из проанализированных 9 заключений об оценке фактического воздействия федеральных законов за 2017-2020 гг. указанные положения не были связаны с правовыми ограничениями для применения цифровых технологий, в том числе цифровизации государственного управления. Кроме того, цикл проведения ОФВ от формирования плана до подготовки заключения об оценке фактического воздействия занимает до двух лет, что делает невозможным оперативное выявление вновь вводимых правовых ограничений для цифровизации государственного управления.

План мониторинга правоприменения в Российской Федерации на 2020 г., утв. распоряжением Правительства РФ от 31 августа 2019 г. № 1951-р, проведение мониторинга в отношении внедрения и применения цифровых технологий не предусматривает. Положение о мониторинге правоприменения в Российской Федерации, утв. Указом Президента РФ от 20 мая 2011 г. № 657, в настоящее время предусматривает возможность проведения мониторинга правоприменения только в плановом режиме либо при наличии соответствующего поручения Президента РФ или Правительства РФ без внесения изменений в утвержденный Правительством РФ план мониторинга. Методика осуществления мониторинга правоприменения в Российской Федерации, утв. постановлением Правительства РФ от 19 августа 2011 г. № 694, предусматривает проведение оперативного мониторинга в течение первого года действия

๓ нормативных правовых актов Российской Федерации, выполнения ре-

을 шений Конституционного Суда РФ и постановлений Европейского суда по правам человека. Кроме того, данная методика не ориентирована на 尺े выявление правовых ограничений для применения цифровых технологий. В рамках механизма мониторинга правоприменения выявление правовых ограничений цифровизации носит фрагментарный характер,

162 а проведение самого мониторинга в отношении отдельных нормативных правовых актов, а не правовых институтов или, применительно к государственному управлению, отдельных государственных фрункций, не позволяет выявлять системные правовые ограничения цифровизации государственного управления. Кроме того, длительный цикл проведения мониторинга правоприменения не позволяет осуществлять оперативное выявление вновь вводимых правовых ограничений.

Выявление и устранение избыточных и обременительных обязательных требований в рамках механизма «регуляторной гильотины» в большей мере связано с интересами бизнеса, а не собственно государственного управления. Вместе с тем требования к применению цифровых технологий и, соответственно, правовые ограничения, как правило, носят «сквоз- 
ной», межотраслевой характер, что делает актуальным применение для их выявления и устранения данного механизма.

В течение I полугодия 2020 г. на заседаниях подкомиссии по совершенствованию контрольных (надзорных) и разрешительных ффункций ФОИВ при Правительственной комиссии по проведению административной реформы вопросы изменения обязательных требований $к$ внедрению и приленению иибровых технологий рассматривались только в рамках 3 из 16 заседаний подкомиссии по совершенствованию контрольных (надзорных) и разрешительных функций ФОИВ при Правительственной комиссии по проведению административной реформы, что составляет $18,75 \%$. Анализ разработанных в рамках механизма «регуляторной гильотины» проектов нормативных правовых актов показал, что, например, в отношении лицензирования из 9 проектов постановлений Правительства РФ, которыми утверждаются новые положения о лицензировании, предоставление в форме электронных документов прямо предусматривается только в 2 (22\%), в 7 (78 \%) сохраняется предоставление документов и копий документов.

Одновременно, в I квартале 2020 г. на Едином портале проектов НПА были размещены разработанные в рамках реализации механизма «регуляторной гильотины» проекты изменений в фредеральные законы «O связи» ${ }^{16}$ и «О персональных данных» ${ }^{17}$. Как отмечено в заключениях $^{18}$ по результатам независимой антикоррупционной әкспертизы указанных проектов, указанные проекты не соответствуют Методике исполнения плана мероприятий ("Дорожной карты»)) по реализации механизма "регуляторной гильотины", содержат новые требования без соответствующей оценки их регулирующего воздействия. Таким образом, выявление правовых ограничений для внедрения и применения цифровых технологий в рамках механизма «регуляторной гильотины» требует активизации работы соответствующей рабочей группы, а также обеспечения ее взаимодействия с рабочими группами федеральных проектов Национальной программы «Цифровая әкономика Российской Федерации».

${ }^{16}$ Проект фредерального закона «О внесении изменений в Федеральный закон «O связи». URL: https://regulation.gov.ru/projects\#npa=99779

${ }^{17}$ Проект федерального закона «О внесении изменений в Федеральный закон «О персональных данных» в части установления основ правового регулирования обязательных требований». URL: https://regulation.gov.ru/projects\#npa=99801

${ }^{18}$ См.: Eøрелов A. А. Заключение по результатам независимой антикоррупционной экспертизы проекта федерального закона «О внесении изменений в Федеральный закон «О связи»"». URL: https://to36.minjust.ru/sites/default/files/ efremov_aa_ake_zakl_mincifra_proektfz_svyaz_99779.pdf ; Его же. Заключение по результатам независимой антикоррупционной экспертизы проекта федерального закона «О внесении изменений в Федеральный закон «О персональных данных» в части установления основ правового регулирования обязательных требований». URL: https://to36.minjust.ru/sites/default/files/efremov_aa_ake_zakl_mincifra_ proektfz_pd_99801.pdf 
Вестник ВГУ. Серия: Право

В докладе РАНХиГС на Гайдаровском форуме 2020 г. ${ }^{19}$ отмечено, что разработка предложений по изменению НПА по итогам проведения экспериментов в 1994-2019 гг. предусматривалась только в 29,1 \% для федеральных законов; в 33,3 \% указов Президента РФ; в 15,5 \% постановлений Правительства РФ.

Экспериментальное нормотворчество активно развивается в 2020 г. В частности, Федеральный закон от 24 апреля 2020 г. № 123-ФЗ, предусматривающий проведение с 1 июля 2020 г. по 30 июня 2025 г. эксперимента по установлению специального регулирования в целях создания необходимых условий для разработки и внедрения технологий искусственного интеллекта в Москве, определяет цели, задачи и основные принципы установления экспериментального правового режима.

Однако, несмотря на декларируемые цели, связанные с обеспечением повышения качества жизни населения, повышением эффективности государственного или муниципального управления, повышением эффективности деятельности хозяйствующих субъектов в ходе внедрения технологий искусственного интеллекта, указанный закон не определяет порядка оценки эбббективности и результативности установления специального регулирования.

В Государственную Думу 17 марта 2020 г. внесен проект федерального закона № 922869-7 «Об экспериментальных правовых режимах в сфере цифровых инноваций в Российской Федерации» ${ }^{20}$, а 12 мая 2020 г. он был принят в первом чтении. В ходе рассмотрения указанного законопроекта в заключениях комитетов Государственной Думы и Правового управления отражены замечания, которые ранее были высказаны в докладе РАНХиГС ${ }^{21}$, в том числе о соотношении вводимых экспериментальных правовых режимов и иных правовых режимов, необходимость оценки результативности и эффективности экспериментальных правовых режимов, в том числе в ходе их реализации.

В 2020 г. приняты решения о продлении сроков проведения экспериментов: по прослеживаемости импортируемых в Россию товаров (постановление Правительства РФ от 6 января 2020 г. № 2 «О внесении изменений в постановление Правительства Российской Федерации от 25 июня 2019 г. № 807»); по маркировке молочной продукции (поста-

164 новление Правительства РФ от 28 февраля 2020 г. № 215 «О внесении изменения в пункт 1 постановления Правительства Российской Федерации от 29 июня 2019 г. № 836»); по НСУД (постановление Правительства РФ от 27 марта 2020 г. № 350 «О внесении изменений в постановление Правительства Российской Федерации от 3 июня 2019 г. № 710»). При этом

${ }^{19}$ См.: Экспериментальные правовые режимы : зарубежный опыт и российский старт / А. А. Ефремов [и др.] ; науч. ред. В. Н. Южаков. М., 2020.

${ }^{20}$ Проект фредерального закона № 922869-7 «Об экспериментальных правовых режимах в сфере цифровых инноваций в Российской Федерации». URL: https:// sozd.duma.gov.ru/bill/922869-7

${ }^{21}$ См.: Экспериментальные правовые режимы : зарубежный опыт и российский старт / А. А. Ефремов [и др.] ; науч. ред. В. Н. Южаков. М., 2020. 
в пояснительных записках к соответствующим постановлениям Правительства РФ отсутствует инфборлаиия о том, почему сроки действия эксперилентов не были правильно определень при их введении; почелу цели эксперилента не были достигнуты в первоначально установленные сроки; как оценивалась и оценивается их результативность и эбфоективность.

Анализ нормативных правовых актов и проектов нормативных правовых актов о проведении экспериментов в 2020 г. показывает, что в рамках их проведения выявление отдельных правовых ограничений прямо предусмотрено только в одном случае, при этом во всех случаях выявлены риски применения цифровых технологий для прав граждан и организаций, которые не учтены при разработке проектов нормативных правовых актов о проведении данных экспериментов.

Проведенный анализ показывает иелесообразность реализаиии следуюших мер для обеспечения систелности выявления и последующего устранения правовых ограничений иифровизаиии государственного управления в Российской Федерации:

- обеспечение взаимодействия рабочих групп, функционирующих в рамках федеральных проектов национальной программы «Цифровая экономика Российской Федерации», и рабочих групп, функционирующих в рамках реализации механизма «регуляторной гильотины», в том числе взаимный обмен информацией о выявленных правовых ограничениях для внедрения и применения цифровых технологий для соответствующей корректировки как мероприятий в рамках федеральных проектов, так и соответствующих проектов НПА, разрабатываемых в рамках механизма «регуляторной гильотины»;

- внесение дополнений в проект постановления Правительства РФ «О мерах по обеспечению эффрективности мероприятий по использованию информационно-коммуникационных технологий в деятельности государственных органов", предусматривающих в отношении планов цифровой трансформации определение всех значимых параметров и условий претерпевающего цифрровую трансформацию государственного управления, в том числе: полномочий государственного органа (при необходимости), административных процедур, структуры государственного органа, полномочий его структурных подразделений и (или) территори$\infty$ альных органов и их структурных подразделений, полномочий соответствующих государственных служащих и квалификационных требований к соответствующим должностям государственной службы, к мероприятиям по адаптации государственных служащих и граждан РФ к введению соответствующих изменений, в том числе повышение квалификации, организационно-штатные мероприятия, информирование граждан об изменении соответствующих государственных функций, государственных услуг или отдельных административных процедур;

- обеспечение прозрачности результатов проводимых экспериментов в сфере применения цифровых технологий, а также определение необходимости выявления правовых ограничений для внедрения и применения 


\section{Вестник ВГУ. Серия: Право}

цифровых технологий в ходе экспериментов и разработки предложений по их устранению как обязательного условия при введении экспериментов;

- разработка механизма оперативного мониторинга правоприменения;

- внедрение в действующие нормотворческие механизмы оценки воздействия правового регулирования на развитие цифровых технологий ${ }^{22}$.

${ }^{22}$ См.: Eøрелиов A. А. Оценка воздействия правового регулирования на развитие информационных технологий : механизмы и методика // Закон. 2018. № 3. C. $45-56$.

Российская академия народного хозяйства и государственной службы при Президенте РФ

Южаков В. Н., директор Центра технологий государственного управления Института прикладньх эконолических исследований, доктор фбилософбских наук, профбессор

E-mail: yuzhakov-vn@ranepa.ru

Ефрелмов А. А., ведущий научный сотрудник Центра технологий государственного управления Института прикладньх эконолических исследований, кандидат юридических наук, доцент

E-mail: efremov-a@ranepa.ru
Russian Presidential Academy of $\mathrm{Na}$ tional Economy and Public

Yuzhakov V. N., Center's Director of Public Management Technologies Center AERI RANEPA, Chief Researcher, Doctor of Philosophical Sciences, Professor

E-mail: yuzhakov-vn@ranepa.ru

Efremov A. A., Leading Researcher of Public Management Technologies Center AERI RANEPA, Candidate of Legal Sciences, Associate Professor

E-mail: efremov-a@ranepa.ru 